\title{
PROPOSTAS DE ATIVIDADES COM MANCHETES DE JORNAIS
}

\section{Maria Eulalia Tomasi Albuquerque}

\author{
"Não é só quem escreve que significa; quem lê também produz sentidos." \\ (Orlandi, 1988, p. 58) \\ "O sentido, portanto, não nasce com a palavra; ao contrário, ele tem uma \\ história." (Ferreira, 1996, p. 41)
}

\section{INTRODUÇÃO}

Nem todos alunos têm o hábito de ler diariamente matérias jornalísticas na íntegra e, com freqüência, eles fazem das manchetes sua fonte de informação. Esse comportamento, talvez, se explique pelo fato de os jovens estarem habituados à dinâmica televisiva, que se caracteriza pela rapidez/concisão com que aborda/informa os fatos.

A manchete é um tópico importante da notícia, pois serve não só para atrair a atenção do leitor, dando-Ihe conhecer sucintamente o assunto abordado, mas também fornecendo-Ihe informações para que ele faça predições a respeito do texto. Em posição privilegiada - no topo do artigo, cobrindo todas as colunas que o compõem inicia a matéria jornalística. Após a manchete, aparece com freqüência, de acordo com Van Dijk (1992), o lied, que é um subtítulo, em letras menores, o qual traz mais informações a respeito da matéria. A manchete e o lied juntos dão o resumo da notícia. Se em chamada de capa, informa também que é um acontecimento importante no cenário nacional, estadual, regional ou local. Então, a manchete, além de noticiar, pode provocar uma tomada de posição do leitor a respeito de determinado fato. Provavelmente, também porque é um texto curto que, junto com o lied, se destaca do corpo das notícias, constitui o tópico mais lido em jornais, mesmo que de forma rápida e acidental.

Como todo professor quer desenvolver o gosto dos alunos pela leitura para que eles se tornem, ao interagir com qualquer tipo de texto, leitores críticos e independentes, pretende-se, neste trabalho: a) refletir a constituição do sentido de manchetes; b) que as sugestões dadas provoquem os estudantes para a leitura. 


\section{PRODUÇÃO E RECEPÇÃO DE MANCHETES}

Parte-se do esquema de comunicação, formulado por Jakobson, que é constituído dos seguintes elementos: mensagem enviada por um emissor a um recebedor, dentro um contexto, por meio de um código e de um canal físico. Nesse processo de comunicação, a concepção de linguagem subjacente é de instrumento de comunicação. Pêcheux (1969) reformula esse esquema à luz da Análise do Discurso e afirma que o envolvimento não é mais das pessoas físicas dos interlocutores, mas o das formações imaginárias que apontam para o lugar que 0 produtor do texto e o leitor atribuem a si próprios, um ao outro e ao referente. Para o autor, também que não há transmissão de informações de um emissor para um recebedor, mas efeitos de sentido que são constituídos pelos leitores. Com essa mudança de ponto de vista e de concepção de linguagem - agora tida como interação - reconhece-se um locutor e um alocutário, um Eu e um TU - interagindo, dos lugares sociais de onde falam ou escrevem, para constituir o sentido do que ouvem ou lêem.

\subsection{O JORNALISTA, PRODUTOR DO TEXTO}

Quem é o produtor do texto? É o jornalista, um sujeito ideológico, que produz textos também ideológicos, nos quais, de forma subjacente, se podem detectar os interesses (econômicos, religiosos, políticos...) dominantes que circulam na sociedade. Através de seus textos, o jornalista interpreta e relata acontecimentos sociais, levando em consideração a concepção de autor com que se identifica e a de leitor, seu público-alvo. Nesse processo, o produtor faz uso de uma linguagem social própria de um grupo social e antecipa as representações acerca do seu leitor, para quem escolhe as estratégias adequadas ao desenvolver o seu discurso. Cita-se, como exemplo, o suplemento Zerou, de Zero Hora, em que os jornalistas fazem uso de uma linguagem próxima da coloquial usada por jovens, que é o público-alvo desse caderno.

\subsection{O LEITOR, RECEPTOR DO TEXTO}

Quem é o leitor?

No outro extremo, como parceiro no processo de produção de texto, está o leitor para quem o texto é dirigido e a quem cabe produzir sentido ao que lê, segundo 
as condições históricas de um determinado momento. É, tal como o jornalista, um sujeito ideológico, que desenvolve suas leituras de acordo com suas condições histórico-sociais e as histórias de leitura dos textos. Decorrente da situação de produção do texto, Van Dijk (1992) reconhece que não existe na recepção compreensão única, porque há diferentes situações de produção, diferentes tipos de discurso, diferentes produtores e diferentes leitores de textos. Ainda intervêm, nesse processo de constituição de sentido, a história pessoal e de leituras do leitor, o objetivo da leitura, a ideologia do leitor e a do produtor do texto. Os leitores aqui considerados são os alunos de ensino médio que se quer reflexivos, participantes e críticos. São, no dizer de Bakhtin (1997, p. 320)

Os outros para os quais o meu pensamento se torna, pela primeira vez, um
pensamento real (e, com isso, real para mim), não são ouvintes passivos,
mas participantes ativos da comunicação verbal. Logo de início, o locutor
espera deles uma resposta, uma compreensão responsiva ativa. Todo
enunciado se elabora como para ir ao encontro dessa resposta. O índice
substancial (constitutivo) do enunciado é o fato de dirigir-se a alguém, de
estar voltado para o destinatário.

Se eles forem proficientes, perceberão o cuidado especial que o jornalista tem ao compor seus textos, tanto com a linguagem verbal quanto com a não-verbal. Esses leitores, a partir da manchete, fazem predições para a matéria, levando em consideração: o jornal que a veicula, o tipo de texto, o jornalista que a assina e a manchete que a anuncia.

\subsection{MANCHETES}

As matérias jornalísticas apresentam os acontecimentos segundo a leitura de mundo e a ideologia dos produtores dos textos e das empresas jornalísticas. Os jornalistas procuram construir uma visão de sociedade de acordo com os interesses políticos e econômicos vigentes ou considerados necessários em determinado momento histórico por uma determinada facção social, conforme reconhece Mariani (1999), citando um excerto do Diário de Virgínia Woolf. Considerando-se esses aspectos, busca-se nesta reflexão apoio na Análise do Discurso, a qual reconhece um vínculo indissociável entre o social e o histórico, de forma que a exterioridade do discurso é constitutiva do próprio discurso. Dizendo de outra forma, o nível lingüístico e sua exterioridade são vinculados. Por isso, Pêcheux (1988) afirma que o sentido de 
um texto não existe de per se, mas ele advém das posições ideológicas que se detectam no processo sócio-histórico em que as palavras emergem, por obra, consciente ou não, daqueles que as empregam. Assim, as marcas que o leitor reconhece na superfície textual, não são ingênuas nem gratuitas; pelo contrário, são decorrências desse momento histórico e ideológico em que se estabelece a interlocução, tendo em vista o contexto de recepção.

Em decorrência disso, percebe-se a necessidade de o leitor conhecer a forma como se estruturam esses textos e os acontecimentos sociais de que emergem. Assim, o bom leitor é o que tem condições de refletir como o texto pode ser compreendido e perceber os jogos de linguagem, de poder, da ideologia que direcionam tais textos. Daí se afirmar que a linguagem não é um código transparente, neutro ou apenas instrumental, porque os sentidos não são transmitidos prontos de um emissor a um recebedor. Ao contrário, os sentidos são construídos através do diálogo entre leitor e texto, através da linguagem, conforme ensina Bakhtin (1997, p. 313).

Pode-se colocar que a palavra existe para o locutor sob três aspectos: como palavra neutra da língua e que não pertence a ninguém: como palavra do outro pertencente aos outros e que preenche o eco dos enunciados alheios; e finalmente, como palavra minha, pois, na medida em que uso essa palavra, numa determinada situação, com uma intenção discursiva, ela já se impregnou de minha expressividade. Sob esses dois últimos aspectos, a palavra é expressiva, mas essa expressividade, repetimos, não pertence à própria palavra: nasce no ponto de contato entre a palavra e a realidade efetiva, nas circunstâncias de uma situação real, que se atualiza através do enunciado individual.

Sobre essa questão, Garcez (1998) tece esta reflexão esclarecedora

\begin{abstract}
Não se trata mais de entender a língua como um objeto aceito a priori, um acervo imutável depositado na memória coletiva, uma herança ou um mecanismo inato ao cérebro do falante, mas trata-se de concebê-la como uma forma de ação, um modo de vida social, em que a situação da enunciação e as condições discursivas são determinantes de sua função e, logo, de seu significado e de sua interpretação.(Garcez, 1998, p. 47)
\end{abstract}

No processo de produção da manchete, o jornalista, de uma forma enxuta, procura dar o máximo de informações aos leitores, ao mesmo tempo que omite as marcas do enunciador, para que o fato anunciado passe ao público-alvo um efeito de objetividade, de distanciamento pessoal, de imparcialidade. Nesse sentido, o jornalista, muitas vezes, insinua sem dizer. 
Exemplo extraído do Jornal Zero Hora, de 08/05/2000, p. 20:

\section{GREVE ACABA, MAS HÁ PERIGO NA ESTRADA}

Sem resolver a questão dos fretes baixo e dos custos, os caminhoneiros adiam as revisões de segurança.

Na composição dessa manchete e desse lied, destacam-se os tempos verbais, que, segundo Weinrich (apud Koch, 1987), são agrupados em dois sistemas temporais. O primeiro - com o predomínio dos tempos: presente, pretérito perfeito composto, futuro do presente, futuro do presente composto e locuções formadas com esses tempos - representam o mundo comentado. O segundo - com prevalência do pretérito perfeito simples, pretérito imperfeito, pretérito mais-que-perfeito, futuro do pretérito e locuções com esses tempos - remetem ao mundo narrado.

Segundo essa teoria, o enunciador, ao empregar os tempos do mundo comentado, demonstra estar engajado, comprometido com o que escreve, ao mesmo tempo que espera uma resposta de seu leitor. O emprego do presente explica-se porque é o ponto inicial dos comentários e da leitura crítica e também presentifica para o leitor um acontecimento que, cronologicamente, já ocorreu.

Nessa manchete, é significativo, por exemplo, o emprego do operador argumentativo "mas", que assinala uma relação semântica de desigualdade entre dois acontecimentos e ressalta direções contrárias: o fim da greve que se opõe à continuação do perigo nas estradas.

O lied completa as informações iniciais, dando ciência ao leitor de que "o perigo nas estradas" refere-se à reação dos caminhoneiros ao fim da greve. Ou seja, porque eles não tiveram as reivindicações atendidas, não farão as revisões de segurança. Isso significa retardar a troca de óleo, de lonas de freio, recauchutar pneus e transportar carga um pouco acima do limite máximo. Percebe-se, aí, uma relação de causalidade entre esses acontecimentos, de forma que a segunda asserção - mas há perigo na estrada - contraria expectativa provocada pela primeira - greve acaba. 


\subsection{PARA ENTENDER A GREVE DOS CAMINHONEIROS}

À guisa de esclarecimento e para a compreensão deste trabalho, retomam-se os acontecimentos que provocaram a greve dos caminhoneiros em maio de 2000, sem se discutir o mérito da questão.

\subsubsection{Causas da greve dos caminhoneiros}

A greve dos caminhoneiros organizada pelo Movimento União Brasil Caminhoneiros foi marcada, em assembléia, no estado do Paraná, para 1ํ de maio de 2000, se o Governo Federal não cumprisse o acordo (com onze reivindicações), firmado em julho de 1999. Esse acordo, conforme acerto na ocasião, seria atendido no prazo de 90 dias, embora meses depois, somente três dos itens acordados tenham sido cumpridos.

O Palácio do Planalto, em convocação, chama o Ministro dos Transportes, o Ministro do Gabinete e de Segurança Institucional e o Ministro da Justiça, para decidirem como enfrentar as manifestações pelo Dia do Trabalho. Todavia as principais preocupações da reunião, conforme Zero Hora, de 1\%/05/2000, era a paralisação dos motoristas junto com a série de ocupações anunciadas pela Confederação Nacional dos Trabalhadores na Agricultura (Contag).

Os caminhoneiros tinham consigo uma pauta de onze reivindicações, incluindo aposentadoria especial e redução da pontuação por infrações de trânsito. Três foram consideradas fundamentais para pôr fim ao movimento:

- redução do pedágio para $\mathrm{R} \$ 1,00$ por eixo de caminhão (hoje a taxa varia de $\mathrm{R} \$ 2,80$ a $\mathrm{R} \$ 4,80)$;

- fim da pesagem por eixo de excesso de peso e criação de uma planilha de custos para a elaboração de uma tabela referencial de frete;

- $\quad$ fim da necessidade de reacomodação da carga em casos de excesso de peso e criação de uma planilha referencial de frete.

Dessas três, o Governo concordou somente com a última e apresentou alternativas para as outras duas.

O Governa lança, então, às vésperas do prazo da segunda greve, um pacote de emergência com as seguintes medidas: instituição do vale-padágio, que transfere o pagamento dos pedágios aos donos das cargas; passe livre aos caminhões de carga em todas as rodovias concedidas pela União até 11/05/2000; regulamentação do desmanche dos caminhões, ou seja, apenas empresas credenciadas seriam autorizadas e teriam de apresentar relatórios periódicos sobre veículos desmontados; nos casos em que a fiscalização ocorre por nota fiscal, o governo admitiu tolerância de 5\% no limite máximo de carga permitido; proibição da conversão de chassis de ônibus em veículos de carga e de transporte de cargas secas em caminhão tanque e aprovação de uma planilha referencial de custos dos fretes, que deverá ser revista em 60 dias (Zero Hora, 04/05/2000).

Todavia a greve acaba sem resolver a questão dos fretes baixos e dos custos crescentes; por isso, os caminhoneiros adiam as revisões de segurança (retardar a troca de óleo, das lonas de freio, recauchutar pneus e transportar 
carga um pouco acima do limite máximo) de seus caminhões (Zero Hora, 08/05/00).

\title{
3. CONSTITUIÇÃO DO CORPUS E DA METODOLOGIA
}

3.1 CORPUS: SETE MANCHETES, CHAMADAS DE CAPA, DO JORNAL "ZERO HORA", DE 1\%05 A 08/05/2000

\author{
CAMINHONEIROS EM GREVE \\ GREVE COMEÇA COM EPISÓDIOS DE VIOLÊNCIA NO SUL \\ GREVE DE CAMINHONEIROS JÁ AMEAÇA ABASTECIMENTO \\ CAMINHONEIROS DECIDEM O RUMO DA GREVE \\ CAMINHONEIROS PROMETEM CANCELAR ATOS VIOLENTOS \\ BRASIL NERVOSO \\ Caminhoneiros e sem-terra sacudiram o país. \\ Governo dá a mais dura resposta da gestão FH \\ TERMINA A GREVE DOS CAMINHONEIROS
}

\subsection{METODOLOGIA}

Analisam-se sete manchetes do Jornal Zero Hora, de 1\%/05 a 08/05/2000, a respeito da greve dos caminhoneiros, segundo a ordem cronológica dos acontecimentos e da edição dos jornais.

Desenvolvem-se duas propostas de trabalho com essas manchetes. $\mathrm{Na}$ primeira, são objeto de análise a linguagem, a ideologia e o lugar do social do jornalista. Na segunda, analisa-se a estrutura dessa rede de informações.

\section{ANÁLISE}

\subsection{PRIMEIRA PROPOSTA}

A primeira manchete - CAMINHONEIROS EM GREVE - anuncia o fato, ou seja, a greve de um modo conciso e impessoal, sem o enunciador emitir qualquer juízo a esse respeito. Limita-se a expressar o acontecimento gerador da matéria - "greve" - e a identificar a categoria profissional em greve - "caminhoneiros". Essa construção frasal passa ao leitor um efeito de objetividade, como se o acontecimento se narrasse 
a si mesmo, sem a intervenção de um enunciador. Transmite a impressão de que o fato é nomeado com isenção de qualquer juízo.

Essa estrutura lingüístico-discursiva não faz a mínima referência às causas da greve, provavelmente, em nome da concisão, do distanciamento pessoal, da objetividade e da ideologia. O jornalista, ao não mencioná-las, isenta o Governo Federal de qualquer responsabilidade a respeito desse acontecimento, como estar em greve não implicasse o fato de uma categoria profissional reivindicar algo de um poder constituído.

A segunda manchete - GREVE COMEÇA COM EPISÓDIOS DE VIOLÊNCIA NO SUL - mantém um efeito de impessoalidade aparente, porque aparece o índice de avaliação "de violência" que predica negativamente "episódios".

Percebe-se a interferência de um enunciador que, indiretamente, assume um posicionamento contra a greve, ao caracterizá-la como um movimento não-pacífico provocador de violência. O jornalista, considerando seu auditório, vincula o movimento grevista à violência. Que leitor gosta de violência? A sociedade não precisa aumentar a dose de violência com que já convive para aceitar mais essa. Ideologicamente, esse enunciador enfatiza a violência como conseqüência de a greve vir descontextualizada da sua causa, ou sela, o acordo não cumprido pelo Governo.

Há, nessa manchete, uma ligação entre o tempo do enunciado e o da enunciação que se acumulam. Isso se explica em virtude de o fato - a deflagração da greve - já ter acontecido, antes da redação da manchete, embora o jornalista empregue o tempo presente. Em outras palavras, o verbo "começa", ainda que se refira a um acontecimento pretérito, faz que a ação se estenda ao presente da notícia, aproximando o leitor desse fato que já ocorreu cronologicamente. É uma estratégia discursiva de que o jornalista se vale para também comprometer o leitor a respeito do que está sendo noticiado.

$\mathrm{Na}$ terceira manchete - GREVE DE CAMINHONEIROS JÁ AMEAÇA O ABASTECIMENTO - o enunciador vê esse movimento classista como prejudicial à sociedade. É possível essa leitura em virtude do emprego do verbo "ameaça". "Ameaçar", segundo Aurélio Buarque de Holanda Ferreira, é "procurar intimidar, meter medo; pôr em perigo, anunciar castigo ou malefício; dar mostras ou indícios de (coisa iminente)". Que cidadão gosta de ser ameaçado? 
Esse verbo tem um sentido tão forte, que provoca preocupação ou temor mesmo antes de a ameaça se concretizar. Apesar de a sociedade ainda não estar privada de gêneros alimentícios e de combustíveis, a escolha do verbo "ameaçar" constitui uma estratégia intimidativa, que sugere ser a greve um mal. O operador argumentativo "já" presentifica a ameaça não apenas uma mera possibilidade; pelo contrário, esse operador traz para o momento presente um perigo que pode (ou não) acontecer.

A ameaça em questão representa a falta de víveres, de combustíveis - itens necessários à sobrevivência individual do ser humano e à tranqüilidade da sociedade. Daí que essa manchete informa o acontecimento ao mesmo tempo que representa o julgamento de um enunciador a respeito do movimento para alcançar uma conclusão prevista e desejada: tornar o leitor de Zero Hora contrário à greve dos caminhoneiros. Daí também porque há não só uma aparente neutralidade do enunciador.

Na quarta manchete - CAMINHONEIROS DECIDEM O RUMO DA GREVE pela primeira vez, aparece um agente explícito com poder de decisão, todavia, ao apontar os caminhoneiros como quem pode decidir o rumo da greve, isenta da esfera do executivo qualquer responsabilidade sobre esse acontecimento e de suas conseqüências. Considerando-se apenas a manchete, é possível a compreensão de que, na deflagração da greve, não houve a conjunção de dois pólos antagônicos em confronto, A leitura seria diferente se as manchetes fizessem menção às causas geradoras do movimento, por exemplo.

A quinta manchete - CAMINHONEIROS PROMETEM CANCELAR ATOS VIOLENTOS - novamente, traz explícitos os agentes da greve. O enunciador reconhece que os caminhoneiros têm legitimidade para cumprirem o que prometeram: o fim dos atos violentos.

Se eles fazem tal promessa é porque têm poder para tal. Daí inferir-se que eles são os provocadores, os responsáveis por esses atos, uma vez que "prometer" significa comprometer-se no sentido de fazer cessar a violência. Esse verbo implica sinceridade do locutor, associada à intenção de cumprir a promessa. Prometer vai além do ato de fala, porque compromete o locutor tanto no presente quanto no futuro. É um presente-futuro. 


\section{Sexta manchete - BRASIL NERVOSO}

Caminhoneiros e sem-terra sacudiram o país

Governo dá a mais dura resposta da gestão FH -

É a única manchete dessa série acompanhada de lied. A manchete concisa "Brasil Nervoso" traz um adjetivo que representa uma avaliação do enunciador acerca do estado em que se encontrava o Brasil naquele momento, tanto do lado dos caminhoneiros e sem-terra, quanto do lado do governo. Esse estado de anormalidade provocado pela greve dos caminhoneiros e pela ação dos sem-terra.

"Nervoso", para Aurélio Buarque de Holanda, significa: "4. Fig. vigoroso enérgico; 5. Fig. Irritado, exaltado, excitado". O verbo "sacudir" remete a uma ação forte, capaz de abalar o Brasil, ou seja, a ação dos caminhoneiros e dos sem-terra é tão forte, que desestabiliza a ordem vigente. É, por isso, ameaçadora. Através desses itens lexicais, percebe-se a tensão gerada por atos dos caminhoneiros e dos semterra em conflito com o Governo. $O$ enunciador evidencia os agentes das ações expressas pelos verbos "sacudiram" e "dá" são de agentes que ocupam lugares sociais antagônicos. Por isso, o jornalista isolou-os em frases autônomas e, aparentemente, sem relação pela ausência de nexos coesivos entre elas.

Na primeira frase do lied - "Caminhoneiros e sem-terra sacudiram o país" estão explícitos a ação e os agentes que provocaram a reação mais dura do Governo $\mathrm{FH}$, expressa na segunda frase. Pela primeira vez, nesse bloco de manchetes, é mencionado o Governo, que ocupa, nesta contenda, lugar oposto aos caminhoneiros e aos sem-terra. $O$ enunciador apresenta índices de avaliação, como o advérbio intensificador "mais" e o adjetivo "dura, na forma superlativa. Essas marcas ressaltam a conseqüência imediata dos atos dos caminhoneiros (e dos sem-terra), que é a ação do Governo, caracterizada como a "mais dura" dentre tantas outras que já praticou. Essa relação de causalidade permite se pensar também que esse enunciador concorda ideologicamente com o governo, porque, ao mencioná-lo pela primeira vez, o faz com avaliações positivas a seu respeito. É um ponto de vista que ele defende e passa a seus leitores. É a situação em que o jornalista insinua sem dizer, e, ao mesmo tempo, fica evidente que a língua não é um código neutro nem transparente. 
$\mathrm{Na}$ última manchete do corpus - Termina a greve dos caminhoneiros novamente assume a palavra um locutor impessoal que apenas relata o fim da greve, passando um efeito de distanciamento do fato, conferindo-Ihe a credibilidade de um analista objetivo.

O autor usa a ordem indireta dos termos na oração, antepondo o verbo ao sujeito. É uma estratégia do jornalista para enfatizar o fim do movimento e, de forma subjacente, realçar a ação do Governo, que soube dura e energicamente defender os interesses sociais. As manchetes anteriores, ao contrário, iniciavam com o sujeito, com os termos da oração em ordem direta, pois interessava chamar a atenção para os agentes responsáveis pelos atos perniciosos à sociedade. É a informação mais relevante a ser captada pelo leitor.

\subsection{SEGUNDA PROPOSTA}

Mesmo empregando os verbos no presente, tempo que não pertence ao mundo narrado, conforme a teoria de Weinrich, pode-se entender que as manchetes encontram-se narrativizadas, ou seja, relatam um conflito, envolvendo personagens (protagonistas e antagonista), que se desenrola no tempo espaços social e geográfico determinados tendo em vista um determinado fim.

É consenso que as narrativas, de um modo geral, têm estrutura de conteúdos semelhantes, conforme Figueiredo (1994). A estrutura canônica das narrativas é formada pelas seguintes categorias: situação inicial, complicação, ação, resolução, situação final e moral; embora esta última não se aplique a todos tipos de narrativas.

Retomando-se as manchetes sobre a greve dos caminhoneiros, pode-se enquadrá-las nas categorias próprias das narrativas simples:

\section{- Situação inicial: CAMINHONEIROS EM GREVE}

*complicação: GREVE COMEÇA COM EPISÓDIOS DE VIOLÊNCIA NO SUL GREVE DE CAMINHONEIROS JÁ AMEAÇA ABASTECIMENTO 
· ação: CAMINHONEIROS DECIDEM O RUMO DA GREVE

CAMINHONEIROS PROMETEM CANCELAR ATOS VIOLENTOS

*resolução: BRASIL NERVOSO

Caminhoneiros e sem-terra sacudiram o país

Governo dá a mais dura resposta da gestão FH

*ação: CAMINHONEIROS DECIDEM O RUMO DA GREVE

CAMINHONEIROS PROMETEM CANCELAR ATOS VIOLENTOS

· situação final: TERMINA A GREVE DOS CAMINHONEIROS

A narrativa constituída pelas manchetes não foi resolvida com sucesso. Pelo contrário, houve perdas para as duas partes em conflito: os caminhoneiros não alcançaram seus objetivos e o governo não resolveu o impasse criado pelo não cumprimento do acordo que ele firmara, em 1999, com os caminhoneiros.

Esse tipo de análise permite que se discuta e se examine a organização de diferentes tipos de textos, como o narrativo e o expositivo, por exemplo. Nas narrativas, para que os alunos possam fazer uma prospectiva a respeito do que lêem/ouvem, ou sela, eles podem antecipar-se à seqüência do texto. Nos textos expositivos, ao contrário, eles fazem uma retrospectiva, relacionando as informações novas com as já dadas, conforme Figueiredo (1994). Esse estudo comparativo permite que os alunos introjetem um processo de leitura conscientemente apreendido e disponham de mais subsídios para efetuarem leituras críticas de textos. 


\section{CONCLUSÃO}

Como já foi realçado anteriormente neste trabalho, as manchetes constituem a fonte de informação de muitos leitores. Se eles restringirem sua leitura somente a esses tópicos, adquirirão conhecimentos parciais e, talvez, perniciosos para a formação de opinião e tomada de posição sobre determinado acontecimento. Todavia, não se deve desprezar essa inclinação para ler textos curtos. Deve-se, sim, a partir daí, buscar outras alternativas de leitura que possibilitem a formação de um leitor crítico e, talvez, despertem-lhe o gosto pela leitura de forma geral.

A respeito da primeira sugestão, lendo somente a série de manchetes publicada por Zero Hora sobre a greve dos caminhoneiros ocorrida no ano 2000, pôdese constatar que essa greve não foi tratada com simpatia pelos jornalistas. Conforme o modo como as manchetes foram redigidas, ou seja, descontextualizadas de suas causas, elas remetem à irresponsabilidade de uma classe que entra em greve e prejudica a sociedade. Todavia, fazendo-se uma retrospectiva dos acontecimentos, fica-se sabendo, em matérias de Zero Hora, de 01/05 a 08/05/00, que a greve foi conseqüência do não cumprimento pelo Governo Federal de um acordo firmado entre ele e os caminhoneiros em 1999. Mas as manchetes desse período, em nenhum momento, mencionaram essas informações.

$\mathrm{Na}$ verdade, os jornais, como formadores de opiniões, agem segundo os interesses políticos e econômicos vigentes em determinado momento. Eles comprometem-se com determinada ideologia. Daí entender-se que entre os lugares sociais ocupados pelas partes em conflito - caminhoneiros e governo - Zero Hora favorece o segundo, uma vez que conotações negativas foram empregadas nas manchetes que se referiam aos caminhoneiros e a seu movimento, mas não as que remetem ao Governo. Daí inferir-se que o efeito objetividade é apenas uma máscara necessária para passar ao leitor a idéia de isenção no julgamento dos fatos anunciados.

Em síntese, as manchetes, ao noticiar a greve, não alcançaram todas as facetas desse fato e, de forma subjacente, manipularam as informações com vista a um fim desejado. Como os sentidos não estão prontos no texto, mas são construídos também por quem lê e vinculam-se às suas condições de produção, se os alunos foram bem preparados para perceber os jogos de linguagem, refletir a escolha dos 
itens lexicais e a ideologia adotada pelo jornal, terão condições de efetuar uma leitura de maior qualidade e defender-se dessas artimanhas.

Em relação à segunda sugestão, as sete manchetes compõem uma narrativa, em que se percebe, pela ação de personagens (caminhoneiros e governo), uma alteração da situação inicial (violência, ação do governo) que mantém entre os fatos uma relação de anterioridade, de concomitância e de posterioridade. Mesmo em textos que não se caracterizam como narrações, pode-se encontrar um componente narrativo, desde que se constate "transformação de situações", como reconhecem Platâo \& Fiorin (1996, p. 229).

As análises das manchetes, quer na primeira sugestão, quer na segunda, poderão servir de elementos provocadores para que os alunos leiam os textos jornalísticos na íntegra, a fim de confirmar as hipóteses por eles formuladas, a partir dos títulos. De qualquer forma, essas possibilidades de leitura poderão ser enriquecidas e, talvez, fazer dos estudantes leitores atentos e habituais.

\section{BIBLIOGRAFIA}

BAKHTIN, Mikahail. Estética da criação verbal. São Paulo: Martins Fontes, 1997.

BRANDÃO, Helena H. Nagamine. Fato político e estratégia discursiva. In ATAS1ํㅡㄹ Congresso Internacional da Associação Brasileira de Lingüística -Conferências e mesas redondas. 1996, p.293-297.

CORTEN, André. Discurso e representação do político. In INDURSKY, Freda e FERREIRA, Maria Cristina Leandro (orgs). Os múltiplos sentidos da Análise do Discurso. Porto Alegre: Sagra e Luzzatto, 1999.

DIJK, Teun Adrianus Van. Cognição, discurso e interação. São Paulo: Contexto, 1999.

FERREIRA, Aurélio Buarque de Holanda. Novo dicionário da língua portuguesa. 2 ed. Rio de Janeiro: Editora Nova Fronteira, 1986.

FERREIRA, Maria Cristina Leandro. O estatuto da equivocidade da língua. In Lima, Marília dos Santos e GUEDES, Paulo Coimbra (Orgs.). Estudos de

Linguagem. Porto Alegre: Sagra: DC Luzzatto, 1996.

. Nas trilhas do discurso: a propósito de leitura, Sentido e interpretação. In

ORLANDI, Eni Puccinelli. A leitura e os leitores. Campinas: Pontes, 1998. 
FIGUEIREDO, Olívia. Escrever: da teoria à prática. In FONSECA, Fernanda Irene (org.). Pedagogia da escrita: perspectivas. Porto: Porto Editora Ltda, 1994.

KOCH, Ingedore G. Villaça. Argumentação e linguagem. São Paulo:Cortez,1987.

MARIANI, Bethania Sampaio Corrêa. Sobre um percurso de análise do discurso Jornalístico - A revolução de 30. In INDURSKY, Freda e FERREIRA, Maria Cristina Leandro (orgs). Os múltiplos territórios da Análise do Discurso. Porto Alegre: Sagra \& Luzzatto, 1999.

MARCONDES, Beatriz, MENEZES, Gilda, TOSHIMITSU, Thaís. Como usar outras linguagens na sala de aula. São Paulo: Contexto, 2000.

ORLANDI, Eni Puccinelli. A incompletude do sujeito. In Sujeito e texto. Série Cadernos PUC-31, EDUC, 1988 A.

. Unidade e dispersão: uma questão do texto e do sujeito. In Sujeito e texto. Série Cadernos PUC-31. EDUC, 1988 B.

O inteligível, o interpretável e o compreensível. In ZILBERMAN, Regina e SILVA, Ezequiel Theodoro da (orgs.). Leitura: perspectivas Interdisciplinares. São Paulo: Ática, 1988 C.

PLATÃO \& FIORIN. Lições de texto: leitura e redação. São Paulo: Ática, 1996.

PÊCHEUX, M. Analyse automathique du discours. Paris: Dunod, 1069.

PFEIFFER, Cláudia Castellanos. O leitor no contexto escolar. In ORLANDI, Eni Puccinelli. A leitura e os leitores. Campinas: Pontes, 1998. 